IZA DP No. 9793

Disentangling Neighborhood Effects in Person-Context Research: An Application of a Neighborhood-Based Group Decomposition

Matt Vogel

Maarten Van Ham

March 2016 


\title{
Disentangling Neighborhood Effects in Person-Context Research: An Application of a Neighborhood-Based Group Decomposition
}

\author{
Matt Vogel \\ University of Missouri - St. Louis \\ Maarten Van Ham \\ Delft University of Technology \\ and IZA
}

Discussion Paper No. 9793

March 2016

\author{
IZA \\ P.O. Box 7240 \\ 53072 Bonn \\ Germany \\ Phone: +49-228-3894-0 \\ Fax: +49-228-3894-180 \\ E-mail: iza@iza.org
}

\begin{abstract}
Any opinions expressed here are those of the author(s) and not those of IZA. Research published in this series may include views on policy, but the institute itself takes no institutional policy positions. The IZA research network is committed to the IZA Guiding Principles of Research Integrity.

The Institute for the Study of Labor (IZA) in Bonn is a local and virtual international research center and a place of communication between science, politics and business. IZA is an independent nonprofit organization supported by Deutsche Post Foundation. The center is associated with the University of Bonn and offers a stimulating research environment through its international network, workshops and conferences, data service, project support, research visits and doctoral program. IZA engages in (i) original and internationally competitive research in all fields of labor economics, (ii) development of policy concepts, and (iii) dissemination of research results and concepts to the interested public.
\end{abstract}

IZA Discussion Papers often represent preliminary work and are circulated to encourage discussion. Citation of such a paper should account for its provisional character. A revised version may be available directly from the author. 


\section{ABSTRACT}

\section{Disentangling Neighborhood Effects in Person-Context Research: An Application of a Neighborhood-Based Group Decomposition}

This paper proposes a framework to assess how compositional differences at the neighborhood level contribute to the moderating effect of neighborhood context on the association between individual risk-factors and delinquency. We propose a neighborhoodbased group decomposition to partition person-context interactions into their constituent components. Using data from the National Longitudinal Study of Adolescent to Adult Health, we demonstrate the extent to which variation in the association between impulsivity and delinquency can be attributed to (1) differences in mean-levels of impulsivity and violence in disadvantaged neighborhoods and (2) differences in coefficients across neighborhoods. The moderating effect of neighborhood disadvantage can be attributed primarily to the stronger effect of impulsivity on violence in disadvantaged neighborhoods, while differences in average levels of violence and impulsivity account for 14 percent and 2 percent of the observed difference, respectively.

JEL Classification: $\quad$ C02, R23

Keywords: $\quad$ person-context research, neighborhood effects, decomposition

Corresponding author:

Matt Vogel

Department of Criminology \& Criminal Justice

University of Missouri - St. Louis

One University Boulevard, 324 Lucas Hall

St. Louis, MO, 63121-4499

USA

E-mail:vogelma@umsl.edu 


\section{INTRODUCTION}

While most scholars acknowledge that both dispositional and ecological factors affect crime and delinquency, extant theories have developed, in large part, emphasizing one over the other. In criminology, two parallel lines of research dominate the field, one stressing individual differences in criminal propensity, and the other stressing the role of broader social conditions in the etiology of criminal behavior. In recent years, scholars have become increasingly interested in how social and spatial environments condition the relationships between individual riskfactors and delinquency. This emerging perspective, referred to here as 'person-context' research, assumes that behavioral outcomes are not the result of individual or environmental factors, but are dependent on who is in what environment (Wikstrom, 2004; Messner and Zimmerman, 2012). The general consensus is that dispositional risk factors, such as impulsivity or low self-control, are contingent on the characteristics of broader ecological contexts, such as the school one attends or neighborhood in which one resides (e.g., Gibson, 2012; Lynam et al., 2000; Vazsonyi et al., 2006; Vogel and Barton, 2013; Zimmerman, 2010; Zimmerman et al., 2015).

Much of the research in this area has focused on the differential effects of impulsivity across neighborhood settings (Gibson, 2012; Lynam et al., 2000; Vazsonyi et al., 2006; Vogel, 2016; Zimmerman, 2010; Zimmerman et al., 2015). Overwhelmingly, the empirical literature demonstrates that structural characteristics and the social processes at work in disadvantaged neighborhoods moderate the influence of impulsivity on criminal behavior. The general consensus is that these differential effects, typically referred to as evidence of 'contextual moderation,' can be explained by neighborhood factors providing greater access to criminogenic opportunities or greater exposure to socialization processes promoting violence over normative behaviors.

Two observations complicate the results presented in prior work in this area. First, a sizable body of literature suggests that neighborhood characteristics directly influence youth offending. For instance, adolescents who reside in economically deprived neighborhoods typically exhibit higher levels of problem behavior than adolescents from more affluent neighborhoods (see Sampson et al., 2002; Kubrin and Weitzer, 2003 for reviews). Second, emerging research suggests that the social processes at play in disadvantaged neighborhoods may contribute to the formation of undesirable personality traits (Hart et al., 2008). From this vantage, economic deprivation, limited informal control, and socialization processes promoting crime and delinquency may place youth from disadvantaged neighborhoods at a higher risk of developing, for instance, impulsive tendencies. As a result, these youth typically report higher levels of delinquency and also display higher levels of impulsivity than those from more affluent areas. It remains unclear whether evidence of contextual moderation uncovered in prior research reflects a 'true' neighborhood effect or developmental processes that give rise to compositional differences in both impulsivity and delinquency across neighborhoods. Disentangling contextual influences from developmental processes is critical to understanding the complex role that neighborhoods play in adolescent behavior.

We propose a neighborhood-based, group decomposition framework to partition the moderating effect of neighborhood context into its constituent parts. This technique assumes that developmental and contextual factors lead to unique data generating processes which differentially affect the estimation of neighborhood-level moderation. We frame our discussion around recent research on impulsivity and neighborhood disadvantage, but these techniques can 
be applied to a broad range of topics linking individuals to broader ecological contexts. We acknowledge that the procedures presented here have been used in most social science disciplines, but with few exceptions, remain underutilized in mainstream criminological research and have yet to be embraced in person-context research.

We begin with an overview of person-context research, focusing on the pathways through which neighborhoods are thought to influence criminal conduct. We then discuss how developmental processes can be viewed as a special type of neighborhood selection, leading to compositional effects that complicate the interpretation of contextual moderation in traditional regression models. After elaborating the basic structure of the decomposition procedure, we demonstrate how it can be leveraged to assess differences in the effect of impulsivity on offending across levels of neighborhood disadvantage among a sample of respondents participating in the National Longitudinal Study of Adolescent to Adult Health (Add Health).

\section{PERSON-CONTEXT RESEARCH IN CRIMINOLOGY}

Person-context research assumes that behavioral risk factors are more strongly associated with criminal behavior in particular social contexts (for a comprehensive overview see Messner and Zimmerman, 2012). An appreciable portion of this research has focused on identifying neighborhood-level mechanisms that either mitigate or exacerbate the association between impulsivity and delinquency. Several studies have reported the effect of impulsivity on offending to be strongest among adolescents living in economically disadvantaged neighborhoods and neighborhoods characterized by low levels of adult supervision (Lynam, et al., 2000; Meier et al, 2008; Jones and Lynam, 2009; Vogel, 2016). Other studies have uncovered the opposite - that the effect of impulsivity is stronger in relatively affluent neighborhoods with high levels of collective efficacy (Zimmerman, 2010; Wikstrom and Loeber, 2000). And, at least two studies have failed to detect any evidence of contextual moderation (Vazsonyi et al., 2006; Zimmerman et al., 2015).

While research in this vein has produced somewhat equivocal results, each of these studies is grounded within a similar theoretical framework and each points to similar mechanisms purported to underlie the stronger effect of impulsivity on delinquency in certain neighborhoods - namely, the differential distribution of criminogenic opportunities. For instance, Lynam and colleagues (2000) draw from routine activities theory (Cohen and Felson, 1979; Osgood et al., 1995; Osgood and Anderson, 2004) and posit that the lack of informal social control in disadvantaged neighborhoods provides greater opportunity for impulsive individuals to engage in rule violating behavior. Zimmerman (2010), on the other hand, argues that disadvantaged neighborhoods present a variety of risk-factors for delinquency (e.g., broken families, exposure to deviant peers). When these external factors are removed, the association between impulsivity and delinquency emerges more clearly. In this case, the lack of exogenous influences in comparatively 'well-off' neighborhoods is the precise reason why impulsivity has a stronger effect on delinquency in these areas. Figure 1 presents a theoretical diagram outlining the hypothesized moderating relationship of neighborhood disadvantage on the association between impulsivity and delinquency typically explored in person-context research. Path A represents the direct effect of impulsivity on offending, and Path B represents the moderating role of neighborhood disadvantage. The dotted line differentiates processes hypothesized to occur at the individual level from those at the neighborhood level - in this case, path A reflects 
an individual level relationship, while path B reflects the moderating role of neighborhood-level processes.

\section{[Figure 1 About Here]}

Drawing from the neighborhood effects literature, an alternative explanation for a stronger effect of impulsivity, or dispositional risk factors more generally, in economically deprived neighborhoods can be attributed to the fact that high-risk individuals are overrepresented in high-risk environments. In traditional thinking on selection effects, this means that people with particular background characteristics differentially select certain types of neighborhoods; for instance, poor people may be more likely to live in economically deprived neighborhoods as housing prices are lower (van Ham and Manley, 2012; van Ham et al., 2012) . However, much of the person-context literature focuses on adolescents and it bears to reason that the non-random distribution of children and adolescents across neighborhoods overwhelmingly reflects the decisions of parents. While it is unlikely that impulsive youths 'choose' to live in poorer neighborhoods, as it is their parent who make residential decisions, it is not unreasonable to assume that family and broader community characteristics associated with neighborhood disadvantage contribute to the greater likelihood that these children develop impulsive traits.

Building from Wikström and Sampson (2003), community context may contribute to individual behavior through two complimentary processes: (1) neighborhoods can affect the presence of situational opportunities in which crime is considered a reasonable option and (2) neighborhoods, through both direct and indirect means, can influence the development of criminal predispositions, such as low self-control or impulsivity. In regards to the former (presence of situational opportunities), neighborhood disadvantage may diminish informal social control and provide greater opportunity for adolescents to engage in unstructured activities with their peers, away from adult chaperones - prime conditions for delinquency (Bernasco et al., 2013; Hoeben and Weerman, 2014; Weerman et al., 2015; Wikstrom and Butterworth, 2006). In this sense, neighborhoods can be seen as having a direct influence on individual behavior sometimes referred to as a 'neighborhood' or 'contextual' effect (Vogel and Jacques, 2016).

In regards to the latter (development of criminal dispositions), neighborhoods can be thought of as a collective form of socialization, whereby the shared monitoring and supervision of youth behavior within the larger community framework helps shape healthy child development (Pratt et al., 2004; Sampson et al., 2002; Leventhal and Brooks-Gunn, 2000; Shaw and McKay, 1942). Disadvantaged neighborhoods, characterized by low levels of cohesion and limited communication among neighbors, may be less adept at creating self-control in children. Moreover, families living in economically deprived communities may face a number of disadvantages, such as single-earner families, unemployment, and poverty, which detract from their ability to adequately socialize their children. Coupled with the absence of community resources to alleviate the burden, children growing up in these areas may experience inconsistent supervision, inconsistent rule enforcement, and inconsistent discipline when they misbehave. As a result of both community and family socialization practices, children may not develop the same executive functions (e.g., the ability to delay gratification) as children from more affluent communities. Indeed, several studies have reported an inverse relationship between neighborhood disadvantage and levels of self-control, in some cases rivaling the effects of family socialization (Pratt et al., 2005; Turner et al., 2005; but see Gibson et al., 2009). In this sense, neighborhood disadvantage may contribute to the development of criminogenic traits like 
impulsivity. It bears to reason that these developmental processes will be stratified by place, leading to a greater concentration of impulsive adolescents in certain areas than others. In other words, developmental processes will give rise to compositional differences in individual riskfactors across neighborhoods

Arguably, the role of neighborhoods in the formation of antisocial traits is more likely to occur during key developmental phases; in the case of impulsivity or self-control, childhood. The more proximate neighborhood mechanisms, particularly those contributing to situational opportunities to offend, will be more salient during adolescence, after criminal propensities are more or less fixed. This is noteworthy, as most of the person-context research has relied on samples of adolescents and young adults, presumably observing individuals well after such developmental phases. Thus, what may appear to be an individual risk factor during adolescence may instead reflect neighborhood influences earlier in the life-course, and what appears to be a differential effect of the dispositional trait on offending across neighborhoods may simply reflect earlier neighborhood developmental processes. While both contextual and developmental mechanisms are important in understanding how neighborhoods mitigate or exacerbate the association between dispositional characteristics and offending, making claims about one requires an understanding of the contributions of the other.

[Figure 2 about Here]

Figure 2 presents an expanded theoretical model of the moderating role of neighborhood disadvantage on the association between impulsivity and delinquency, incorporating the role of developmental and contextual influences. In this figure, Path $\mathrm{C}$ represents the direct effect of neighborhood-level disadvantage on offending (as examined in many classic studies of neighborhood effects). This pathway is assumed in most person-context research and can be directly assessed through the main effect of neighborhood disadvantage in standard regression models. Path D reflects the developmental processes that may lead to higher levels of impulsivity among adolescents who grow up in disadvantaged communities. Unlike the direct effect of neighborhood disadvantage, this pathway is rarely considered and its influence cannot be gleaned from a standard regression model. Thus, to truly understand the moderating role of neighborhood context on the association between impulsivity and offending, researchers need not only examine paths $\mathrm{A}$ and $\mathrm{B}$, but also need to carefully consider the role of $\mathrm{C}$ and $\mathrm{D}$.

\section{DECOMPOSING THE INTERACTION EFFECT}

The standard approach to assessing neighborhood moderation in person-context research involves estimating a regression model in which neighborhood characteristics, impulsivity, and their product term are included alongside a series of control variables to predict some form of delinquency. The regression equation takes on the basic form ${ }^{1}$ :

\footnotetext{
${ }^{1}$ Some studies employ multilevel or hierarchical linear models (HLMs) to partition the variance in the dependent variable between individuals and neighborhoods. Unlike the methods presented here, HLM models require (1) nested data - that is, respondents clearly situated within broader neighborhood units, (2) a large number of neighborhoods, and a (3) large number of respondents in each neighborhoods. Few extant data sources meet this requirement. Moreover, the models require that variance can be specified on both L1 and L2, which is not possible with count or categorical models - those most commonly employed in criminological research (Sweeten, 2012).
} 


$$
\mathrm{Y}=\mathrm{a}+\mathrm{b}_{1} \mathrm{X}_{1}+\mathrm{b}_{2} \mathrm{X}_{2}+\mathrm{b}_{3} \mathrm{X}_{1} \mathrm{X}_{2}
$$

Where $\mathrm{Y}$ refers to a scale of delinquency, $\mathrm{b}_{1}$ refers to the slope of impulsivity (denoted by Path A in Figure 2), $b_{2}$ refers is the slope of neighborhood disadvantage (Path $C$ ), and $b_{3}$ is the product term for the neighborhood disadvantage * impulsivity (Path B). A significant coefficient for $b_{3}$ is usually considered sufficient evidence of contextual moderation, and is often interpreted as the expected change in the slope of $b_{2}$ across levels of neighborhood disadvantage - in other words, how neighborhood context mitigates or exacerbates the effect of impulsivity on offending.

This interpretation is problematic, as the interaction term, in part, reflects compositional differences in impulsivity across neighborhoods (due to relationship D in Figure 2). For the reasons outlined above, we might expect average levels of impulsivity to be higher in economically disadvantaged neighborhoods. Likewise, while the purported mechanisms vary, a large body of criminological research suggests that levels of offending are, on average, higher among youth residing in economically disadvantaged neighborhoods (Kubrin \& Weitzer, 2003; Sampson, 2002). These two observations suggest that $\mathrm{Y}$ and $\mathrm{X}_{1}$ will increase with neighborhood disadvantage. In the traditional regression model, these higher averages can generate a statistically significant coefficient for $\mathrm{b}_{3}$ without any true difference in the slope of $\mathrm{b}_{1}$ across neighborhoods. Thus, to sufficiently make claims about contextual moderation, researchers need to rule out the possibility that the observed coefficient is not driven by higher averages levels of impulsivity and delinquency alone (as demarcated in paths $\mathrm{C} \& \mathrm{D}$ ).

The issue of developmental versus contextual effects can be viewed as a special version of a more general problem identified in the social science literature: identifying the extent to which differences in rates across groups reflects differences in group composition. While these techniques have been utilized in other disciplines, they have yet to be employed in personcontext research. Oaxaca (1973) and Blinder (1973) independently proposed a relatively straightforward means to address this problem, as it applied to gender differences in earnings. The same basic approach also applies here. In the standard framework, group-based differences can be attributed to two factors - differences in levels and differences in slopes. In the earnings nomenclature, this means that a difference in income between males and females could reflect, in part, higher average education among males (levels) and the portion that cannot be explained by educational differences (e.g., the unexplained portion) would then be attributed to a true interaction effect. ${ }^{2}$ In the case of neighborhood context and impulsivity, the differences in levels can be viewed as analogous to the differential distribution of individual risk-factors across neighborhoods (Paths C and D), while the 'unexplained' part of the interaction could be interpreted as 'neighborhood moderation' (Path B).

In the simplest application, the decomposition involves a four-step process. The first step is to collapse the proposed moderator into a dichotomy, in this case differentiating respondents who live in 'disadvantaged' neighborhoods from all other neighborhood configurations. Second, average levels of impulsivity and offending can be assessed by comparing means across

Thus, the strategy presented here is an alternative to the HLM framework when the computational requirements cannot be met.

${ }^{2}$ Notably, similar strategies have also been applied in the criminological literature to examine differences in offending between males and females (e.g., Botchkovar \& Broidy, 2013; Botchkovar et al., 2015), and racial / ethnic differences in arrest (Kirk, 2008) and incarceration (Vogel and Porter, 2015). 
neighborhood groupings. If there are no differences in the average levels impulsivity, then the strategy presented here is unnecessary. Third, two separate regression equations are estimated, one for respondents living in disadvantaged neighborhoods, and the second for respondents living in all other neighborhoods such that:

and

$$
\hat{y}_{\mathrm{H}}=\mathrm{a}_{\mathrm{H}}+\mathrm{b}_{\mathrm{H}} \mathrm{X}_{\mathrm{H}}
$$

$$
\hat{y}_{\mathrm{L}}=\mathrm{a}_{\mathrm{L}}+\mathrm{b}_{\mathrm{L}} \mathrm{X}_{\mathrm{L}}
$$

In these equations $\hat{y}$ is the predicted level of the outcome of interest (e.g., self-reported offending), $a$ is the regression constant, $X$ is the mean level of the main independent variables (e.g., impulsivity), and $b$ is the regression coefficient. The subscript $H$ refers to respondents living in neighborhoods with high levels of disadvantage and $L$ refers to respondents living in neighborhoods with low levels of disadvantage. Similar to Equation 1, contextual moderation can be assessed by comparing $b_{H}$ and $b_{L}$, in this case, the Clogg Test for the equality of coefficients can be used to assess statistical significance (Paternoster et al., 1998). ${ }^{3}$ The difference in average levels of self-reported delinquency can then be expressed as the difference in predicted levels of delinquency between equations 2 and 3:

$$
\left(\hat{\mathrm{y}}_{\mathrm{H}}-\hat{\mathrm{y}}_{\mathrm{L}}\right)=\left(\mathrm{a}_{\mathrm{H}}+\mathrm{b}_{\mathrm{H}} \overline{\mathrm{x}}_{\mathrm{H}}\right)-\left(\mathrm{a}_{\mathrm{L}}+\mathrm{b}_{\mathrm{L}} \overline{\mathrm{x}}_{\mathrm{L}}\right)
$$

Which can be expanded into the Blinder and Oaxaca decomposition such that:

$$
\left(\hat{\mathrm{y}}_{\mathrm{H}}-\hat{\mathrm{y}}_{\mathrm{L}}\right)=\mathrm{b}_{\mathrm{H}}\left(\overline{\mathrm{x}}_{\mathrm{H}}-\overline{\mathrm{x}}_{\mathrm{L}}\right)+\overline{\mathrm{x}}_{\mathrm{L}}\left(\mathrm{b}_{\mathrm{H}}-\mathrm{b}_{\mathrm{L}}\right)
$$

In this equation $\left(\hat{y}_{H}-\hat{y}_{L}\right)$ is the expected difference in self-reported delinquency between adolescents living in disadvantaged and non-disadvantaged neighborhoods. $\mathrm{b}_{\mathrm{H}}\left(\overline{\mathrm{x}}_{\mathrm{H}}-\overline{\mathrm{x}}_{\mathrm{L}}\right)$ represents the portion of the difference in delinquency across neighborhoods that can be attributed to compositional differences - in this case, higher average levels of impulsivity in disadvantaged neighborhoods. The final component, $\bar{x}_{\mathrm{L}}\left(\mathrm{b}_{\mathrm{H}}-\mathrm{b}_{\mathrm{L}}\right)$, is the 'unexplained' part of the interaction effect, in this case, the portion of the interaction that can be attributed to a stronger effect of impulsivity on delinquency in disadvantaged neighborhoods.

The two component model can be expanded slightly such that:

$$
\left(\hat{\mathrm{y}}_{\mathrm{H}}-\hat{\mathrm{y}}_{\mathrm{L}}\right)=\mathrm{b}_{\mathrm{L}}\left(\overline{\mathrm{x}}_{\mathrm{H}}-\overline{\mathrm{x}}_{\mathrm{L}}\right)+\overline{\mathrm{x}}_{\mathrm{L}}\left(\mathrm{b}_{\mathrm{H}}-\mathrm{b}_{\mathrm{L}}\right)+\left(\mathrm{b}_{\mathrm{H}}-\mathrm{b}_{\mathrm{L}}\right)\left(\overline{\mathrm{x}}_{\mathrm{H}}-\overline{\mathrm{x}}_{\mathrm{L}}\right)
$$

In this case, the difference in delinquency across neighborhoods is decomposed into three components, the difference in mean levels of impulsivity $\left[b_{L}\left(\bar{x}_{H}-\bar{x}_{L}\right)\right]$, the difference in coefficients $\left[\overline{\mathrm{x}}_{\mathrm{L}}\left(\mathrm{b}_{\mathrm{H}}-\mathrm{b}_{\mathrm{L}}\right)\right]$, and a third component that accounts for the part of the difference that can be attributed to the interaction between levels and coefficients $\left[\left(b_{H}-b_{L}\right)\left(\bar{x}_{H}-\bar{x}_{L}\right)\right]($ Daymont and Andrisani, 1984). This third component, as discussed in greater detail below, overcomes scaling issues in $\mathrm{X}$.

Equations 5 and 6 allow researchers to decompose the differences in predicted levels of $y$ into two main components. However, we may also be interested in the extent to differences in $\mathrm{Y}$ (delinquency), in addition to differences in $\overline{\mathrm{x}}$ (impulsivity), affect the observed interaction. In this

${ }^{3} \mathrm{Z}=\left(\mathrm{b}_{\mathrm{H}}-\mathrm{b}_{\mathrm{L}}\right) / \sqrt{ }\left(\mathrm{se}_{\mathrm{H}}^{2}+\mathrm{se}_{\mathrm{L}}{ }^{2}\right)$ 
case, we can expand the equation 5 once more to yield a four component solution (Jones and Kelley, 1984):

$$
\left(\hat{\mathrm{y}}_{\mathrm{H}}-\hat{\mathrm{y}}_{\mathrm{L}}\right)=\left(\mathrm{a}_{\mathrm{H}}-\mathrm{a}_{\mathrm{L}}\right)+\mathrm{b}_{\mathrm{L}}\left(\overline{\mathrm{x}}_{\mathrm{H}}-\overline{\mathrm{x}}_{\mathrm{L}}\right)+\overline{\mathrm{x}}_{\mathrm{L}}\left(\mathrm{b}_{\mathrm{H}}-\mathrm{b}_{\mathrm{L}}\right)+\left(\mathrm{b}_{\mathrm{H}}-\mathrm{b}_{\mathrm{L}}\right)\left(\overline{\mathrm{x}}_{\mathrm{H}}-\overline{\mathrm{x}}_{\mathrm{L}}\right)
$$

Here $\left[\left(a_{H}-a_{L}\right)\right]$ is the difference in the adjusted intercepts of the two groups or the proportion of the observed interaction that can be attributed to variation in mean levels of delinquency (Y) across neighborhoods. $\left[b_{\mathrm{L}}\left(\overline{\mathrm{x}}_{\mathrm{H}}-\overline{\mathrm{x}}_{\mathrm{L}}\right)\right]$ is the component attributed to differences in levels of impulsivity, or how impact of impulsivity on delinquency for someone living in a high disadvantage neighborhood would change if they were living in a low disadvantage neighborhood. $\overline{\mathrm{x}}_{\mathrm{L}}\left(\mathrm{b}_{\mathrm{H}}-\mathrm{b}_{\mathrm{L}}\right)$ is the differences in the effect on impulsivity on delinquency across neighborhoods and $\left[\left(b_{H}-b_{L}\right)\left(\bar{x}_{H}-\bar{x}_{L}\right)\right]$ is the residual component interpreted as the difference in the interaction between mean levels of impulsivity and coefficients across neighborhoods. ${ }^{4,5}$ Examining each of these components as a proportion of the raw difference in predicted levels of delinquency, $\left(\hat{\mathrm{y}}_{\mathrm{H}}-\hat{\mathrm{y}}_{\mathrm{L}}\right)$, provides a means to quantify the contribution of compositional differences in delinquency and impulsivity to the observed moderating effect of neighborhood disadvantage on the association between the two. Thus, the third component provides the estimate of 'neighborhood moderation' and the first and second components provide the estimates of developmental processes that give rise to compositional differences across neighborhoods (paths C and D).

\section{APPLICATION}

\section{Data}

In effort to demonstrate the utility of this technique, we decompose a series of regression models addressing the association between impulsivity and delinquency among respondents participating in the National Longitudinal Study of Adolescent to Adult Health, a representative survey of adolescents enrolled in high school during the 1994-95 academic year and followed through early adulthood. This study includes detailed information on self-reported criminal behavior, personality characteristics, and a host of information pertaining to adolescent development. In addition to self-reported questionnaire items, decennial census data has been appended to respondents' home addresses, allowing us to generate measures of neighborhood disadvantage at the tract-level. The present analysis draws on a sample of 12,935 respondents who participated in the first two waves of the survey, spanning the years 1994-1996. Notably, the Add Health data

\footnotetext{
${ }^{4}$ This example applies to a hypothetical regression model in which neighborhood disadvantage is collapsed into a dichotomy. The same general framework can be applied to ordinal or continuous measures of neighborhood disadvantage. This extension would require expanding the number of regression equations to equal the number of categories, $\mathrm{K}$, of the neighborhood measure. The decomposition could then be replicated by comparing $\mathrm{Y}$ and $\mathrm{X}$ for each of the possible pairwise comparisons, selecting the neighborhood with the highest level of disadvantage as the referent.

${ }^{5}$ The decomposition presented here assumes the parameter estimates are generated from an OLS regression. This approach has also been expanded to apply to binary outcomes (Fairlie, 1999; 2005), quantile regression, and counterfactual models (Machado and Mata, 2005). Bauer and Sinning (2008) provide a generalized decomposition for non-linear models with discrete and limited dependent variables. The NLDECOMPOSE routine in Stata can handle these more complex modeling strategies (Sinning, Hahn, and Bauer, 2008; Jann, 2008).
} 
have been used in several previous studies examining contextual moderation in the impulsivitydelinquency relationship (Vazsonyi et al., 2006; Vogel and Barton, 2013; Vogel, 2015). ${ }^{6}$

\section{Measures}

The primary dependent variable is self-reported violence. It is a cumulative measure of the number of the following acts the respondent in which the respondent engaged during the 12 months prior to the Wave 2 interview: (1) injuring someone badly enough to need medical attention, (2) shooting or stabbing someone, (3) using or threatening to use a weapon to get something from someone (4) participating in a group fight, (5) using a weapon in a fight, (6) pulling a knife or gun on someone, (7) getting into a serious physical fight.

Impulsivity is measured by the extent to which respondents agreed with the following statement: when making decisions, you usually go with your 'gut feeling' without thinking too much about the consequences of each alternative. Neighborhood disadvantage was measured as a standardized index of the percent of a respondents neighborhood receiving welfare, the percent living at or below poverty, the percent unemployed, and percent of female headed households $($ alpha $=0.923)$. The regression models also control for race, gender $(1=$ female $)$, age, and family structure (two-parent family $=1$ ).

\section{RESULTS}

Table 1 presents the descriptive statistics for the variables included in the analysis. The analytic sample was roughly 51 percent female, 20 percent non-Hispanic black, 17 percent Hispanic, and 8 percent non-Hispanic other race. The average age was 15.3 years, and 55 percent of respondents live with both biological parents. Respondents reported an average level of impulsivity of 3.02 on a five-point scale.

\section{[Table 1 About Here]}

Table 2 presents the results from a regression model in which self-reported violence was regressed on the control variables, impulsivity, neighborhood disadvantage, and the interaction of impulsivity*neighborhood disadvantage. Consistent with much of the prior work in this area, impulsivity was associated with higher levels of offending, and neighborhood disadvantage moderated this association, such that effect of impulsivity on offending was amplified at higher levels of neighborhood disadvantage.

\section{[Tables 3 \& 4 About Here]}

In order to decompose the interaction, we collapsed the neighborhood disadvantage index at the 75th percentile to create a dichotomy differentiating 'disadvantaged' neighborhoods from all other neighborhoods. Census tracts with scores in the top quartile were coded as 'disadvantaged' while the remaining tracts were coded as 'not-disadvantaged.' We then estimated separate regression models for respondents living in neighborhoods at the top-quartile of disadvantage and respondents living in all other neighborhoods (Table 3). Consistent with the

\footnotetext{
${ }^{6}$ Regression models are presented with clustered standard errors to adjust for the non-random distribution of respondents across census-tracts.
} 
models presented in Table 2, we find that the effect of impulsivity on self-reported violence is stronger among respondents living in disadvantaged neighborhoods relative to those living in more affluent neighborhoods (relationship B in Figure 2; $[Z=1.92$; one-tailed test $]$ ). We next generated predicted levels of self-reported violence in disadvantaged and non-disadvantaged neighborhoods by substituting the mean level of impulsivity into equations 2 and 3, respectively. This yields the constituent terms for equation 7. For instance, the mean level of impulsivity in disadvantaged neighborhoods is 3.09; substituting this value into the regression equation (holding the other covariates constant) provides a $\hat{y}$ of $1.689[\hat{y}=a+b \bar{x}]$. Table 4 presents the summary statistics from these subsequent regressions.

The results of the decomposition analysis indicate that roughly 81 percent of the observed interaction between impulsivity and neighborhood disadvantage can be attributed to differences in the slope of impulsivity across neighborhoods (Table 5). Compositional differences in selfreported violence (14 percent - Path C in Figure 2) and impulsivity (2 percent - Path D in Figure 2) make up the remainder of the observed interaction. Collectively, these findings suggest that much of the observed interaction can be attributed to 'contextual moderation' - that is, that the effect of impulsivity on violence is stronger in economically disadvantaged neighborhoods. However, a non-trivial proportion, just under 16 percent, can be attributed to the differential concentration of high-risk (i.e., delinquent and impulsive) adolescents in disadvantaged neighborhoods.

[Table 5 About Here]

\section{DISCUSSION}

This study proposes a neighborhood-based, group decomposition strategy as a descriptive tool to help quantify the contribution of compositional effects in studies examining how neighborhood context shapes the relationships between individual risk factor and delinquency. This was motivated, in part, by the recognition that neighborhood characteristics can influence individual behavior through both developmental and contextual pathways. From this vantage, personcontext interactions may reflect a stronger effect of dispositional factors on offending in certain neighborhoods, or they may reflect compositional differences in both dispositional characteristics and delinquency across neighborhoods thus complicating the interpretation of contextual moderation, when uncovered. The decomposition framework presented here allows researchers to partition observed differences between groups into components representing differences in composition and differences in coefficients. Such techniques provide a relatively intuitive means to bolster claims about the developmental and contextual underpinnings often assumed in person-context models of behavior.

Using an applied example from the Add Health study, the results of our decomposition indicate that the stronger effect of impulsivity on violence in disadvantaged neighborhoods was primarily a result of contextual factors. We can interpret this as evidence of something unique in economically disadvantaged neighborhoods that increases the effect of impulsivity on offending. Drawing from prior research in this area, this may suggest that disadvantaged neighborhoods provide greater criminogenic opportunities than more affluent communities. The 'explained' portion of the decomposition suggests that developmental processes may still be at play, as 
average levels of delinquency and impulsivity were higher in disadvantaged neighborhoods, but these compositional differences mattered less than the contextual effect.

We encourage researchers to implement these techniques as a sensitivity analyses in their own work. Insofar as there is apriori reason to assume compositional differences between groups (as was the case with the example presented here), it seems useful to demonstrate the extent to which these differences drive interaction effects. We caution researchers from concluding they have uncovered evidence of contextual moderation when compositional differences account for the majority of the observed difference across groups. However, we also encourage researchers to present results in which compositional factors are primarily responsible for these differences, as the mechanisms driving compositional effects are meaningful in and of themselves.

The techniques presented here are not limited to studies examining the moderating role of neighborhood context on the association between individual risk factors and delinquency; rather, they are a useful resource for researchers interested in theoretical models of behavior combining individual and contextual factors more generally. These techniques could be used to examine, for instance, the contribution of student composition to school-level differences in victimization, or to partition gene $\mathrm{X}$ environment interactions into compositional and environmental components. These techniques can be applied to any criminological analyses examining interaction effects in which group-composition may play a meaningful role.

It is important to note that the decompositions reflect an exercise in variance partitioning. While these analyses provide some insight into the structure of the interaction effects, they do little to expound the causal processes underlying the stronger effect of impulsivity on violence in disadvantaged neighborhoods. Thus, these procedures allow us to conclude with relative certainty that the tract-level interactions are not statistical artifacts; however, the mechanisms underlying these effects remain to be determined. Likewise, we do not present this approach as an alternative to correcting regression models for endogeneity. Researchers who want to 'remove' the confounding effects of composition remain well-served to employ standard counterfactual models, such as fixed-effects regressions, propensity score models, or instrumental variable approaches.

\section{Limitations}

The limitations of decomposition techniques have been well documented in the econometric literature (e.g., Jones, 1983; Jones and Kelley, 1984; Lin, 2007), but warrant some discussion. First, the results of these procedures are contingent on the category chosen as the referent. In the application presented here, disadvantaged neighborhoods. The choice of the reference group will alter the decomposition procedure, as the choice of the base category will affect the estimation of the coefficients in the regression equation (and, as a result, the relative contribution of each component to the overall difference). Second, in the standard 2-component decomposition, the interpretation of the 'unexplained' portion (e.g., the difference in slopes) is sensitive to scaling decisions and this component only has a meaningful interpretation for variables which have a natural zero point (Jones and Kelley, 1984). This issue, however, is resolved in the three - and four - component decompositions. Third, the procedure presented here assumed a binary moderator, in this case comparing 'disadvantaged' and 'non-disadvantaged' neighborhoods. Of course, collapsing continuous variables into dichotomies truncates meaningful variation in neighborhood disadvantage. To address this issue, researchers could employ the same framework and decompose the differences at various points of the neighborhood disadvantage index (e.g., one and two standard deviations above / below the mean). Fourth, the decomposition utilizes 
point estimates, thus ignoring the standard error of the coefficients. Although a bit beyond the purview of the present analysis, a handful of scholars have proposed ways to incorporate standard errors into the traditional decomposition framework (e.g., Lin, 2007). Finally, and perhaps most importantly, the decomposition does not provide leverage to determine what is driving the difference in slopes, only the extent to which mean levels of $\mathrm{X}$ and $\mathrm{Y}$ contribute to the observed interaction.

\section{Conclusion}

Limitations aside, the neighborhood-based, group decomposition is a useful heuristic tool for researchers interested in the direct and moderating effects of contextual influences on adolescent behavior. While the approach is commonplace in other social science disciplines, the decomposition framework is rarely utilized in criminological research. Unlike many of the methods de' jure in our discipline, this technique is relatively intuitive, computationally straightforward, and does not necessitate complex modeling strategies. In regards to the personcontext literature in particular, we encourage researchers to simultaneously consider developmental and contextual influences in theoretical models linking individual behavior to broader social ecologies, and caution readers against placing too much stock in one mechanism without considering the contribution of the other. The decomposition framework provides a useful means to this goal.

\section{Acknowledgements}

We would like to thank Ryan D. King, Steven F. Messner, Jaap Nieuwenhuis, and Kyle Thomas for feedback on earlier drafts of this paper. Tim McCuddy, Brittany Jaecques, and Kaylin Haff provided invaluable assistance with this project. All errors and omissions remain our own. The research leading to these results has received funding from the European Research Council under the European Union's Seventh Framework Programme (FP/2007-2013) / ERC Grant Agreement n. 615159 (ERC Consolidator Grant DEPRIVEDHOODS, Socio-spatial inequality, deprived neighbourhoods, and neighbourhood effects); and from the Marie Curie programme under the European Union's Seventh Framework Programme (FP/2007-2013) / Career Integration Grant n. PCIG10-GA-2011-303728 (CIG Grant NBHCHOICE, Neighbourhood choice, neighbourhood sorting, and neighbourhood effects).This research uses data from Add Health, a program project directed by Kathleen Mullan Harris and designed by J. Richard Udry, Peter S. Bearman, and Kathleen Mullan Harris at the University of North Carolina at Chapel Hill, and funded by grant P01-HD31921 from the Eunice Kennedy Shriver National Institute of Child Health and Human Development, with cooperative funding from 23 other federal agencies and foundations. Special acknowledgment is due to Ronald R. Rindfuss and Barbara Entwisle for assistance in the original design. Information on how to obtain the Add Health data files is available on the Add Health website (http://www.cpc.unc.edu/ addhealth). No direct support was received from grant P01HD31921 for this analysis.

\section{REFERENCES}

Bauer, T.K., and Sinning, M. (2008). An extension of the Blinder-Oaxaca decomposition to nonlinear models. Advances in Statistical Analyses, 92, 197-206. 
Bernasco, W., Ruiter, S., Bruinsma, G.J.N, Pauwels, L.J.R., and Weerman, F. (2013). Situational causes of offending: A fixed-effects analysis of space-time budget data. Criminology, $51,895-926$.

Botchkovar, Ekaterina V. and Broidy, Lisa (2013). Parenting, self-control, and the gender gap in heavy drinking: the case of Russia. International Journal of Offender Therapy and Comparative Criminology, 57, 357-376.

Botchkovar, E., Marshall, I.H., Rocque, M. \& Posick, C. (2015). The Importance of Parenting in the Development of Self-Control in Boys and Girls: Results from a Multinational Study of Youth. Journal of Criminal Justice, 43, 133-141.

Blinder, A.S. (1973). Wage discrimination: Reduced from and Structural Estimates. Journal of Human Resources, 8, 436-455.

Cohen L.E., \& Felson M. (1979). Social change and crime rate trends: a routine activity approach. American Sociological Review, 44, 588-608.

Daymont, T.N. \& Andrisani, P.J. (1984) Job presences, college major, and the gender gap in earnings. Journal of Human Resources, 19, 408-428

Fairlie, R.W. (1999). The absence of the African-American owned business: An analysis of the dynamics of self-employment. Journal of Labor Economics, 17, 80-108.

Fairlie, R.W. (2005). An extension of the Blinder-Oaxaca decomposition technique to logit and probit models. Journal of Economic and Social Measurement, 30, 305-316.

Gibson, C.L. (2012). An investigation of neighborhood disadvantage, low self-control, and violent victimization among youth. Youth Violence and Juvenile Justice, 10(1), 41-63.

Gibson, C. L., Sullivan, C. J., Jones, S., \& Piquero, A. R. (2009). "Does It Take a Village?": Assessing Neighborhood Influences on Children's Self-Control. Journal of Research in Crime and Delinquency.

Hart, D., Atkins, R., \& Matsuba, M. K. (2008). The association of neighborhood poverty with personality change in childhood. Journal of Personality and Social Psychology, 94(6), 1048

Hoeben, E. \& Weerman, F. (2014). Situation conditions and adolescent offending: Does the impact of unstructured socializing depend on its location? European Journal of Criminology, 11, $481-499$.

Jann, B. (2008). The Blinder-Oaxana decomposition for linear models. Stata Journal, 8, 453479.

Jones, F. L. (1983). On decomposing the wage gap: A critical comment on Blinder's method. Journal of Human Resources, 18, 126-130.

Jones, F. L., \& Kelley, J. (1984). Decomposing differences between groups: A cautionary note on measuring discrimination. Sociological Methods and Research, 12, 323-343.

Jones, S., \& Lynam, D. R. (2009). In the eye of the impulsive beholder: The interaction between impulsivity and perceived informal social control on offending. Criminal Justice and Behavior, 36(3), 307-321.

Kirk, D. S. (2008). The neighborhood context of racial and ethnic disparities in arrest. Demography, 45(1), 55-77.

Kubrin, C. \& R. Weitzer. 2003. New directions in social disorganization research. Journal of Research in Crime and Delinquency, 40, 374 - 402.

Leventhal, T. \& Brooks-Gunn, J. (2000). The neighborhoods they live in: the effects of neighborhood residence on child and adolescent outcomes. Psychological Bulletin, 126, 309-337. 
Lin, E. S. (2007). On the standard errors of Oaxaca-type decompositions for inter-industry gender wage differentials. Economics Bulletin, 10(6), 1-11.

Lynam, D. R., Caspi, A., Moffitt, T. E., Wikstrom, P., Loeber, R., \& Novak, S. (2000). The interaction between impulsivity and neighborhood context on offending: The effects of impulsivity are stronger in poorer neighborhoods. Journal of Abnormal Psychology, 109, 563-574.

Machado, J.A.F. \& Mata, J. (2005). Counterfactual decomposition of changes in wage distributions using quantile regression. Journal of Applied Economics, 20, 445-465.

Messner, Steven F. \& Zimmerman, G.M. (2012). Community-level Influences on Crime and Offending. In The Oxford Handbook on Crime Prevention, edited by Brandon C. Welsh and David P. Farrington, Oxford University Press, New York, pp. 155-172.

Meier, M. H., Slutske, W. S., Arndt, S., and Cadoret, R. J. (2008). Impulsive and callous traits are more strongly associated with delinquent behavior in higher risk neighborhoods among boys and girls. Journal of Abnormal Psychology, 117, 377-385.

Osgood, D.W., and Anderson, A.L. (2004). Unstructured socializing and rates of delinquency. Criminology, 42, 519-549.

Osgood, D. W., Wilson, J.K., Bachman, J.G., O'Malley, P.M., \& Johnston, L.D. (1996). Routine activities and individual deviant behavior. American Sociological Review, 61, 635-655.

Oaxaca, R. 1973. Male-female wage differentials in urban labor markets. International Economic Review, 14, 693-709.

Paternoster, R., Brame, R., Mazerolle, P., \& Piquero, A.R. (1998). Using the correct statistical test for the equality of regression coefficients. Criminology, 36, 859-866.

Pratt, T.C., Turner, M.G., \& Piquero, A.R. 2004. Parental socialization and community context: a longitudinal analysis of the structural sources of low self-control. Journal of Research in Crime and Delinquency, 41, 219-243.

Sampson, R.J. (2002). Transcending tradition: New directions in community research, Chicago style. Criminology, 40, 213-230.

Shaw, C.R., \& McKay, H.D. (1942). Juvenile delinquency and urban areas. Chicago, Ill.

Sinning, M., Hahn, M., \& Bauer, T.K. (2008). The Blinder-Oaxaca decomposition for nonlinear regression models. The Stata Journal, 8, 480-492.

Turner, M.G., Piquero, A.R., \& Pratt, T.C. 2005. "The school context as a source of selfcontrol." Journal of Criminal Justice 33:327-339.

Vazsonyi, A. T., Cleveland, H.H., \& Wiebe, R.P. (2006). Does the effect of impulsivity on delinquency vary by level of neighborhood advantage?, Criminal Justice and Behavior, 33, 511-541.

van Ham, M. \& Manley, D. (2012). Neighbourhood effects research at a crossroads: Ten challenges for future research, Environment and Planning, 44, 2787-2793.

van Ham, M., Manley, D., Bailey, N., Simpson, L. \& Maclennan D. 2012. New Perspectives. In van Ham, M., Manley, D., Bailey, N., Simpson, L. \& Maclennan, D. (eds) Neighbourhood Effects Research: New Perspectives. Chapter 1, pp 1-22. Springer: Dordrecht.

Vogel, M., and Barton, M. (2013). Impulsivity, school context, and school misconduct. Youth \& Society, 45(4), 455-479.

Vogel, M. (2016). The Modifiable areal unit problem in person-context research. Journal of Research in Crime and Delinquency, 53, 112-135. 
Vogel, Matt and Lauren Porter. (2015). "Toward a demographic understanding of incarceration disparities: Race, ethnicity, and age-structure.” Journal of Quantitative Criminology.

Weerman, F. M., Bernasco, W., Bruinsma, G.J.N., \&Pauwels, L.J.R. (2013). When Is Spending Time With Peers Related to Delinquency? The Importance of Where, What, and With Whom. Crime \& Delinquency.

Wikström, P.O.H. \& Butterworth, D.A. (2006). Adolescent crime. Individual differences and lifestyles, Routledge.

Wikström, P.O.H., \& Loeber, R. (2000). Do disadvantaged neighborhoods cause well-adjusted children to become adolescent delinquents? A study of male juvenile serious offending, individual risk and protective factors, and neighborhood context. Criminology, 38, 11091142.

Wikstrom P.O.H, \& Sampson R.J. (2003). "Social mechanisms of community influences on crime and pathways in criminality." In: Lahey, B.B., Moffitt, T.E., \& Caspi, A. (eds) Causes of conduct disorder and juvenile delinquency. Guilford Press, New York.

Wikström P.O.H. (2004). Crime as alternative: Towards a cross-level situational action theory of crime causation. In McCord, J (ed) Beyond Empiricism: Institutions and Intentions in the Study of Crime, Advances in Criminological Theory. Transaction, New Brunswick.

Wooldridge, J. M. (2005). Simple solutions to the initial conditions problem in dynamic, nonlinear panel data models with unobserved heterogeneity. Journal of applied econometrics, 20, 39-54.

Zimmerman, G. M. (2010). Impulsivity, offending, and the neighborhood: Investigating the person-context nexus. Journal of Quantitative Criminology, 26, 301-332.

Zimmerman, G. M., Botchkovar, E. V., Antonaccio, O., \& Hughes, L.A. (2015). Low selfcontrol in "bad" neighborhoods: Assessing the role of context on the relationship between self-control and crime. Justice Quarterly, 0(0), 1-29. 
Table 1: Descriptive Statistics ( $\mathrm{N}=12,935)$

\begin{tabular}{rcccc}
\hline \hline & Mean (Prop) & SD & Min & Max \\
\cline { 2 - 5 } Age & 15.31 & 1.6 & 12 & 19 \\
Female & 0.51 & ---- & 0 & 1 \\
NH Black & 0.20 & ---- & 0 & 1 \\
Hispanic & 0.17 & ---- & 0 & 1 \\
NH Other & 0.08 & ---- & 0 & 1 \\
Intact Family & 0.55 & ---- & 0 & 1 \\
Impulsivity & 3.02 & 1.12 & 1 & 5 \\
Neighborhood Disadvantage & 0.00 & 0.87 & -1.12 & 3.87 \\
\hline
\end{tabular}

Table 2: Regression of Self-Reported Violence on

Impulsivity, Neighborhood Disadvantage, and Interaction $(\mathrm{N}=12,935)$

\begin{tabular}{|c|c|c|c|c|c|c|}
\hline & \multicolumn{3}{|c|}{ Model 1} & \multicolumn{3}{|c|}{ Model 2} \\
\hline & $\beta$ & se & & $\beta$ & se & \\
\hline Intercept & 1.34 & 0.17 & $* * *$ & 1.14 & 0.17 & *** \\
\hline Age & -0.07 & 0.01 & *** & -0.06 & 0.01 & *** \\
\hline Female & -0.28 & 0.02 & *** & -0.28 & 0.02 & \\
\hline NH Black & 0.12 & 0.06 & * & 0.12 & 0.06 & * \\
\hline Hispanic & 0.18 & 0.06 & ** & 0.18 & 0.06 & ** \\
\hline NH Other & 0.03 & 0.07 & & 0.03 & 0.07 & \\
\hline Intact Family & -0.10 & 0.03 & $* * *$ & -0.10 & 0.03 & *** \\
\hline Neighborhood Disadvantage & 0.03 & 0.02 & & 0.03 & 0.02 & \\
\hline Impulsivity & 0.06 & 0.01 & $* * *$ & 0.06 & 0.01 & *** \\
\hline Dis*Impulsivity & ----- & ----- & & 0.03 & 0.01 & ** \\
\hline
\end{tabular}

Table 3: Regression of Self-Reported Violence on Impulsivity across Neighborhood Type $(\mathrm{N}=12,935)$

\begin{tabular}{rcccccl}
\hline & \multicolumn{3}{c}{ Disadvantaged } & \multicolumn{3}{c}{ Non-Disadvantaged } \\
& \multicolumn{3}{c}{ Tracts } & \multicolumn{3}{c}{ Tracts } \\
\cline { 2 - 7 } Intercept & 1.34 & 0.33 & $* * *$ & 1.31 & 0.18 & $* * *$ \\
Age & -0.06 & 0.02 & $* * *$ & -0.72 & 0.03 & $* * *$ \\
Female & -0.26 & 0.07 & $* * *$ & -0.29 & 0.03 & $* * *$ \\
NH Black & 0.09 & 0.07 & & 0.20 & 0.08 & $*$ \\
Hispanic & 0.28 & 0.10 & $*$ & 0.16 & 0.05 & $* *$ \\
NH Other & 0.26 & 0.19 & & 0.06 & 0.03 & \\
Intact Family & -0.21 & 0.06 & $* * *$ & -0.07 & 0.03 & $*$ \\
Impulsivity & 0.11 & 0.03 & $* * *$ & 0.04 & 0.02 & $* *$ \\
\hline$* \mathrm{p}<0.05 ; * * \mathrm{p}<0.01 ; * * * \mathrm{p}<0.001$ & & & & & &
\end{tabular}


Table 4: Summary Statistics of Impulsivity and Violence across Neighborhood Type

\begin{tabular}{rrrl}
\hline \hline \multicolumn{3}{c}{ advantaged isadvantaged } \\
\cline { 2 - 4 } Tracts & Tracts & Difference \\
Mean Impulsivity & 3.093 & 2.998 & 0.095 \\
Impulsivity Slope & 0.112 & 0.043 & 0.069 \\
a & 1.342 & 1.305 & 0.037 \\
Y-hat & 1.689 & 1.434 & 0.255 \\
\hline
\end{tabular}

Table 5: Decomposition of Difference in Impulsivity - Violence Association across Neighborhood Type

\begin{tabular}{rcrr}
\hline \hline Component & & Raw & Percent \\
\hline Total Difference & $\left(\hat{\mathrm{y}}_{\mathrm{H}}-\hat{\mathrm{y}}_{\mathrm{L}}\right)$ & 0.255 & $100.0 \%$ \\
Portion Explained by Differences in Mean Violence & $\left(\mathrm{a}_{\mathrm{H}}-\mathrm{a}_{\mathrm{L}}\right)$ & 0.037 & $14.5 \%$ \\
Portion Explained by Differences in Mean Impulsivity & $\mathrm{b}_{\mathrm{L}}\left(\overline{\mathrm{x}}_{\mathrm{H}}-\overline{\mathrm{x}}_{\mathrm{L}}\right)$ & 0.004 & $1.6 \%$ \\
Portion Explained by Differences in Impulsivity Slope & $\overline{\mathrm{x}}_{\mathrm{L}}\left(\mathrm{b}_{\mathrm{H}}-\mathrm{b}_{\mathrm{L}}\right)$ & 0.207 & $81.2 \%$ \\
Residual Difference & $\left(\mathrm{b}_{\mathrm{H}}-\mathrm{b}_{\mathrm{L}}\right)\left(\overline{\mathrm{x}}_{\mathrm{H}}-\overline{\mathrm{x}}_{\mathrm{L}}\right)$ & 0.007 & $2.7 \%$ \\
\hline
\end{tabular}


Figure 1: Hypothesized Moderating Association of Neighborhood Disadvantage on Impulsivity-Delinquency

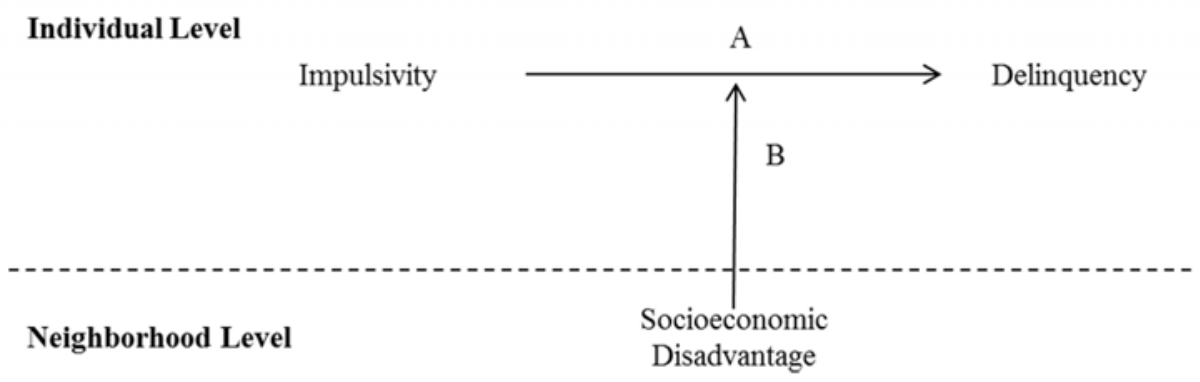

A - Direct Effect of Impulsivity on Delinquency

B - Moderating Effect of Disadvantage on the Impulsivity-Delinquency Association

Figure 2: Hypothesized Direct and Moderating Effects of Neighborhood Disadvantage on Impulsivity, Delinquency, and the Relationship between Impulsivity and Delinquency

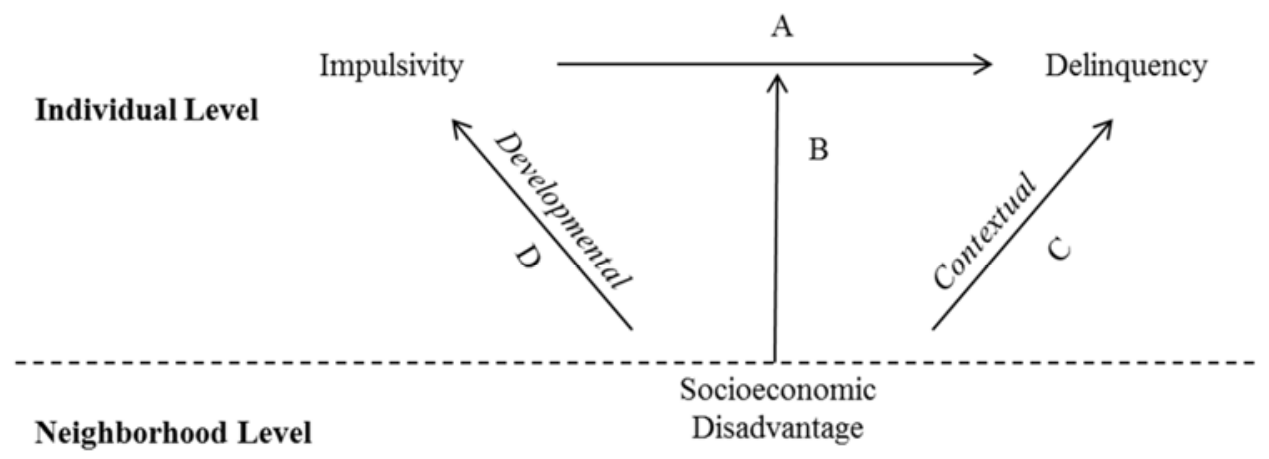

A - Direct Effect of Impulsivity on Delinquency

$\mathrm{B}$ - Moderating Effect of Disadvantage on the Impulsivity-Delinquency Association

C - Direct Effect of Neighborhood Disadvantage on Delinquency

D - Direct effect of Neighborhood Disadvantage on Impulsivity 